\title{
A Bibliometric Analysis of the One Hundred Most Cited Studies in Psychosomatic Research
}

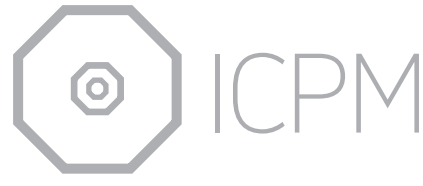

\author{
S. Mudasser Shah ${ }^{\mathrm{a}}$ Tauseef Ahmad ${ }^{\mathrm{b}}$ Suzhen Chen ${ }^{\mathrm{a}}$ Gao Yuting ${ }^{\mathrm{a}}$ \\ Xiaoyun Liu ${ }^{\mathrm{a}}$ Yonggui Yuan ${ }^{\mathrm{a}}$ \\ ${ }^{a}$ Department of Psychosomatics and Psychiatry, ZhongDa Hospital, School of Medicine, Southeast University, \\ Nanjing, China; ${ }^{b}$ Department of Epidemiology and Health Statistics, School of Public Health, Southeast University \\ Nanjing, Nanjing, China
}

The bibliometric method is mainly composed of citation analysis, which is the source of impact factors. Papers with a high number of citations are considered central in research. Therefore, top and highly cited papers provide evidence and information about research trends and scientific progress in a specific field. To the best of our knowledge, no studies have been published on the 100 most cited studies in psychosomatics, a wide interdisciplinary field that is concerned with the interaction of biological, psychological, and social factors in regulation of the balance between health and disease.

The present work aimed to identify and characterize the 100 most cited studies in psychosomatic research. A bibliometric design was used. On January 21, 2021, the Web of Science Core Collection database was searched for relevant studies in psychosomatics using "psychosomatic" as the keyword. Full texts and abstracts were screened by the authors independently to find the top cited articles in psychosomatics. Only studies with the term "psychosomatic" in the title were included. The authors extracted the data from the selected 100 most cited articles, which were exported into Microsoft Excel 2019 and HistCite $^{\mathrm{TM}}$ for Windows. Any disagreement was resolved by discussion. The 100 most cited studies were selected based on the number of citations (Table 1).

The 100 most cited studies were published in 53 different journals (5,065 cited references) and conducted by 245 authors, with an overall 15,691 global citations. Psychosomatic Medicine was the leading journal, with 25 published studies, followed by Psychotherapy and Psychosomatics $(n=8, \mathrm{GCS}=1,088)$. Of the included studies, $82 \%$ were published as research articles while $11 \%$ were published as review articles. The USA was the topranked country, with $37 \%$ of the studies cited 6,069 times. The most productive institute in psychosomatics was Harvard University, which published 5\% of the studies with 867 citations. The most prolific authors were Z.J. Lipowski ( $n=5$; 785 citations), J.W. Pennebaker $(n=3$; 789 citations), and G.A. Fava ( $n=3 ; 456$ citations). The most cited study was "Psychosomatic Disease and the Visceral Brain: Recent Developments Bearing on the Papez Theory of Emotion." It was authored by P.D. Maclean, published in 1949 in the Journal of Psychosomatic Medicine, and cited 738 times. The largest number of studies was published in English and developed countries. karger@karger.com

(c) 2021 S. Karger AG, Basel

www.karger.com/pps

Karger"
Correspondence to:

S. Mudasser Shah, mudasser.shah35@gmail.com

Yonggui Yuan, yygylh2000@ sina.com 
Table 1. The 100 most cited studies on psychosomatics

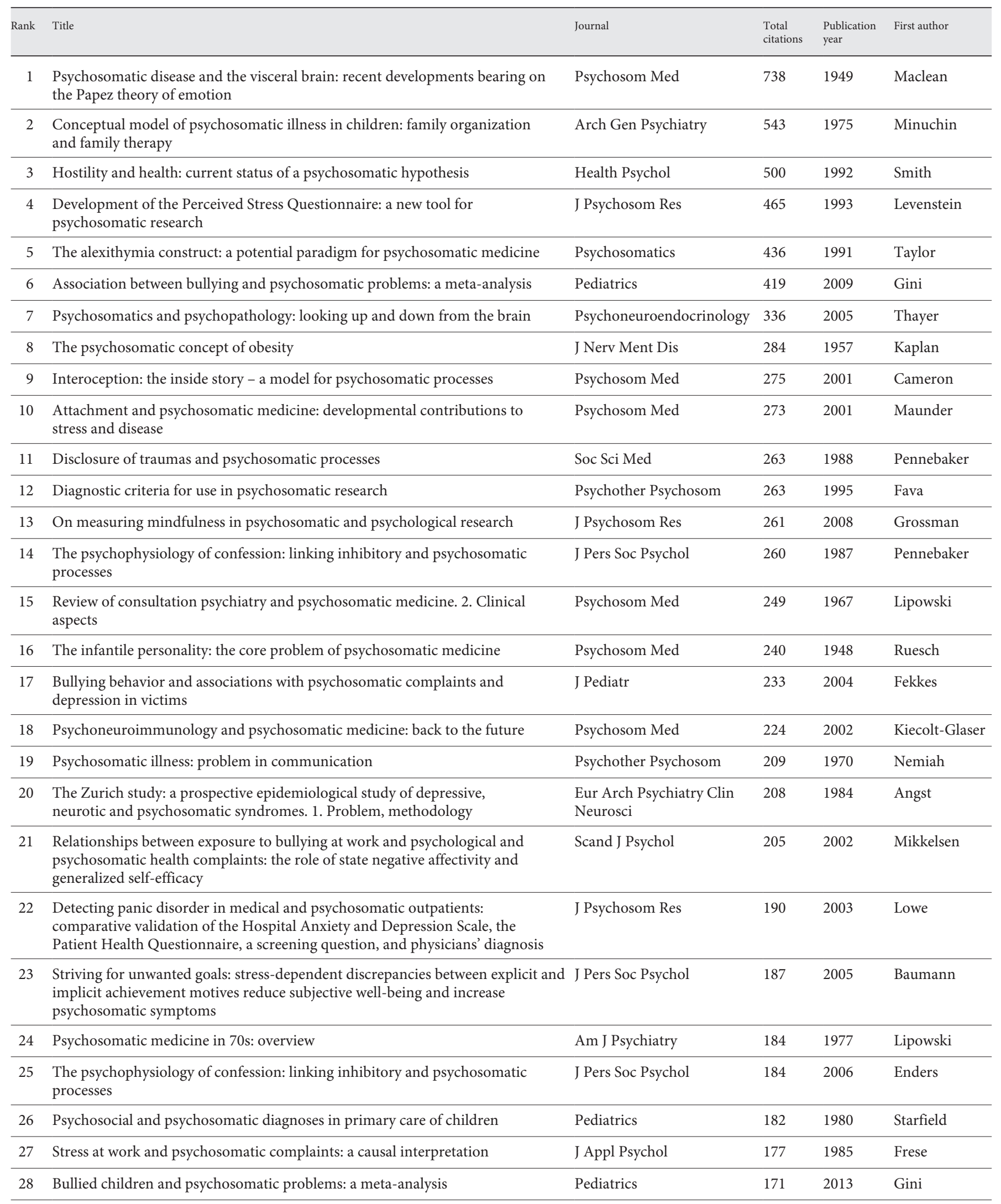


Table 1 (continued)

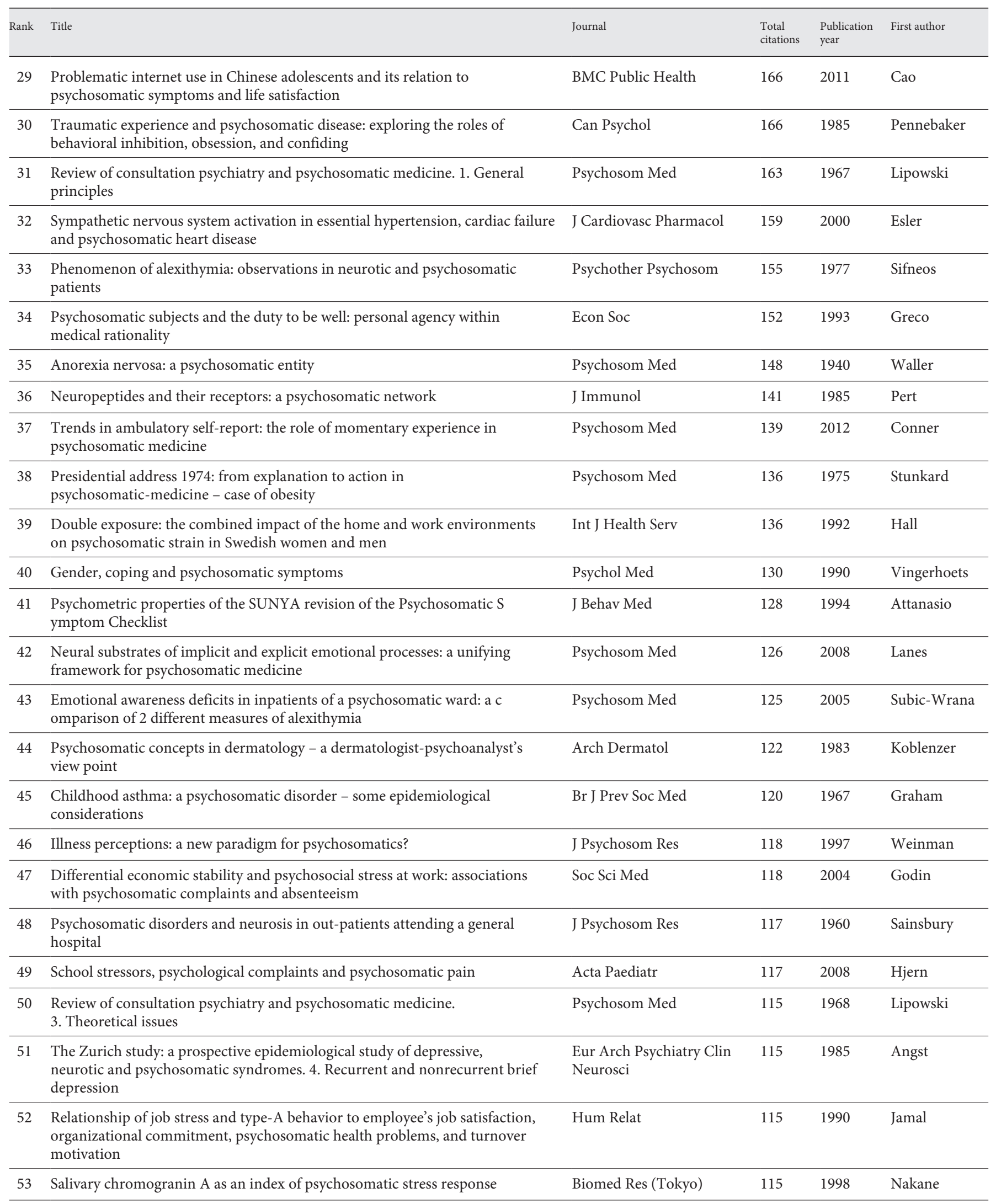


Table 1 (continued)

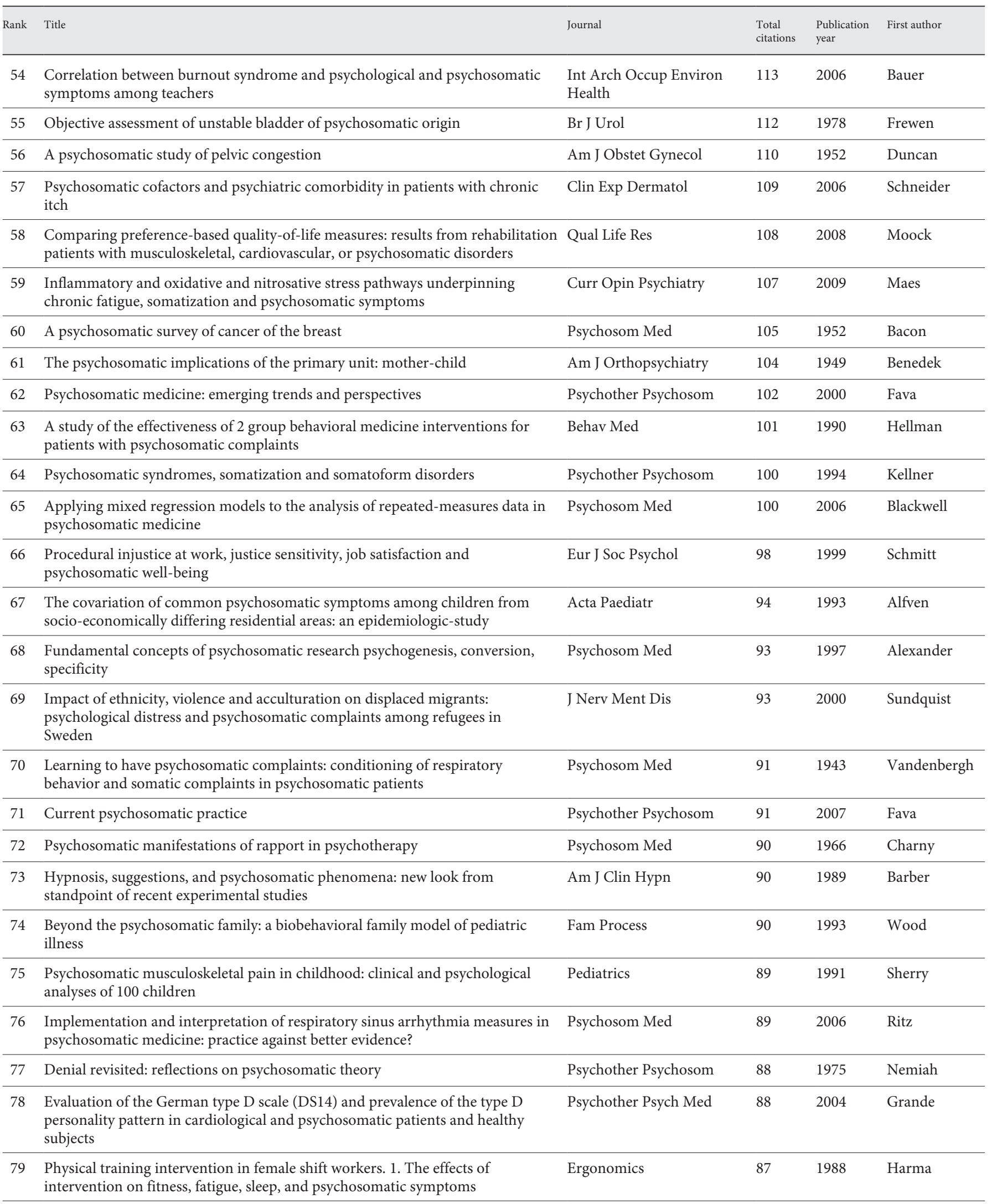


Table 1 (continued)

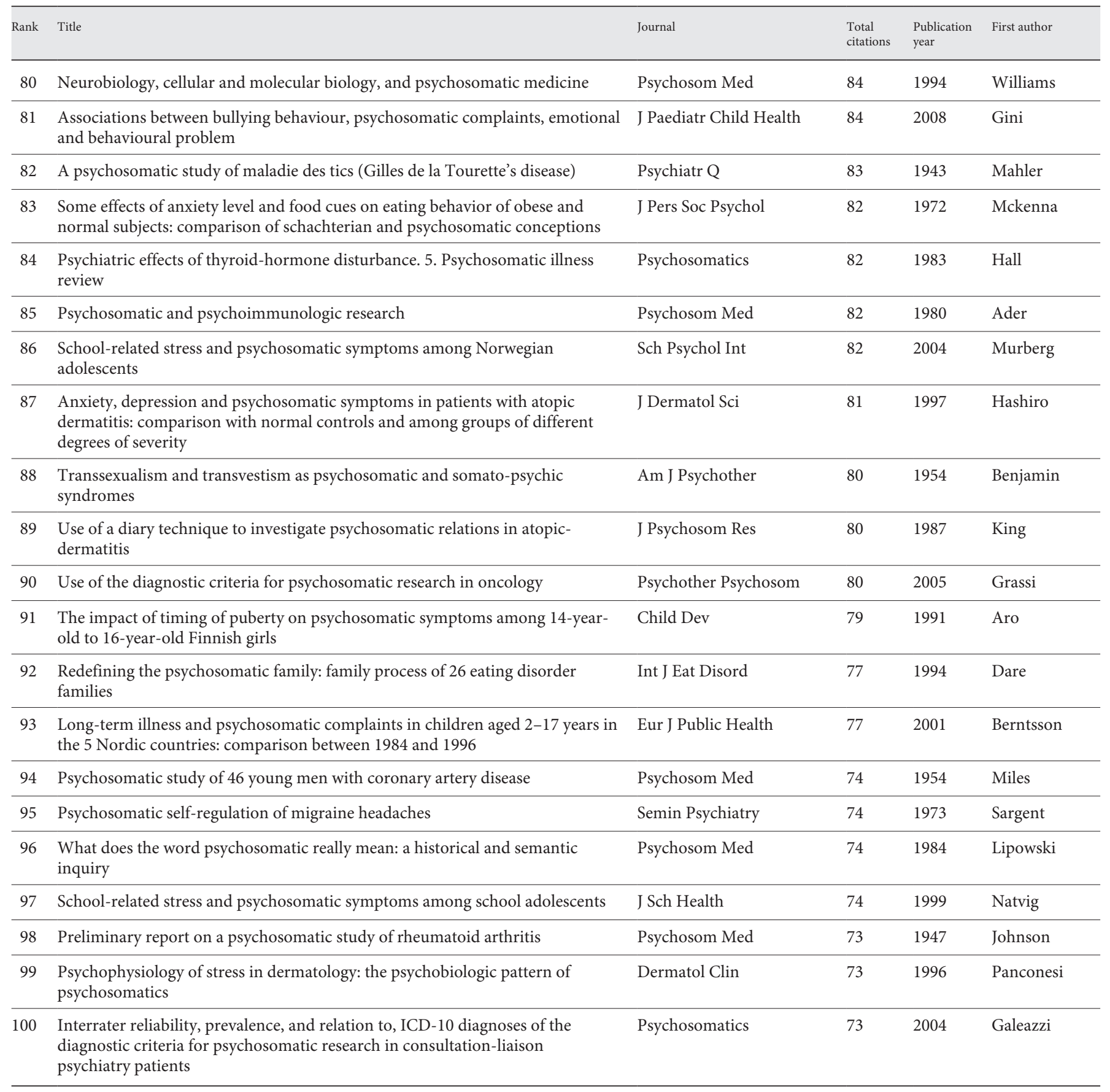

The present results might help researchers to identify trends in psychosomatic research, targeted journals, specialized institutions, and highly qualified authors. However, they should be considered with caution since they were strongly influenced by the choice to include only papers with the word "psychosomatic" in the title, which, for instance, excluded seminal papers in psychosomatics such as "The Need for a New Medical Model: a Challenge for Biomedicine" [Science. 1977; 196: 129-36] by G. Engel. 


\section{Acknowledgment}

We acknowledge Southeast University (Nanjing, China) for providing free online access to the Web of Science Core Collection database.

\section{Statement of Ethics}

No human or animal subjects were involved in this study. Therefore, no ethical approval was required.

\section{Conflict of Interest Statement}

The authors have no conflict of interests to declare.

\section{Funding Sources}

This study received no financial support. 